\title{
Cost of diseases in Brazil: breast cancer, enteritis, cardiac valve disease and bronchopneumonia
}

\author{
Armando Arredondo, Lejeune Y. Lockett, Esteban de lcaza \\ Instituto Nacional de Salud Pública de México - Cuernavaca, México
}

\begin{abstract}
The results from the need to develop methodologies for performing cost anaiysis in developing countries, principally in the region of Latin America, were studied. It, furthermore, serves to generate knowledge from an economic evaluation in order to support decision-making related to the organization of health systems, particularly in the efficient use of resources which are allocated for the provision of medical services. Two chronic diseases (breast cancer and cardiac valve disease) and two infections (enteritis and bronchopneumonia) were selected for the study. The results recommend the use of a valid methodology for economic cost analysis of any disease to be studied and the use of this information in the decision-making process.
\end{abstract}

Health care costs. Cost control. Health economics.

\section{Introduction}

It is evident to all that the extraordinary increase in the cost of health services and consequently the necessary increase in expenditure in recent years has produced multiple inequities in the governments of developing countries and over all among the planners, managers and health policy makers". The demand for health care does not diminish; It become ever more diversified. The elevated cost of distinct alternatives of action in this period of economic recession has imposed a heavy burden on the national budgets which the governments are trying to reduce ${ }^{1 ?}$.

In the process of planning, it is necessary to recognize the importance of applying economic analyses to the health sector. During the first Ibero-American Public Health Conference in August 1988, a scheme of interinstitutional cooperation was created which eventually led to an advance in the promotion of sectorial leadership. In order to complete this task, one of the areas analyzed since the last World Assembly of Health, was precisely that which promoted the understanding of the interrelations between economics and health ${ }^{8,18}$.
Economic issues are gaining growing importance in the field of medical care. They prove to be increasingly important in measuring the increased participation of the health sector in the gross domestic product ${ }^{27}$. Health workers must be alerted to the changes that are coming about and the economic forces that they influence, such as related jobs that exert a considerable impact on the employment market ${ }^{24}$.

In the case of Latin America, and particularly in Brazil, an important force has arisen, in recent years, with a view to satisfy the health needs of the population. Nevertheless, to date. according to official data, there exist a considerable percentage of the population which lack health services, and which fundamentally affect, the mass of the population located outside the urban areas and within the low income areas ${ }^{21}$.

According to the understanding of the economic meaning of efficiency, if patients were not treated at or refered to a superior level of care, if this were possible, their diagnosis and treatment would be adequately provided at an lower level ${ }^{2.25}$.

The problem results from the lack of techniques and procedures compounded by the lack of parameters for the measurement of productivity,

Reprints: Armando Arredondo - Departamento de Investigación en Financiamiento y Tecnología para la Salud - Instituto Nacional de Sahud Pública de México - Al. Universidad 655 - Col. St. Maria Ahuacatitlan - 62508 Cuernevaca. Morelos - México - Fax: (5.73) 11 -24.68

Received in 10.20.1994. Approved in 7.10.1995. 
costs, and procedures for interaction among different levels of care: these factors together translates into a health system without an adequate basis for the management and evaluation of its interaction and efficiency. On the other hand. in view of the health conditions prevalent in the majority of Latin American countries it is necessary to take the trends of the change in the epidemiological patterns in developing countries as a basis for analysis". The theory of these epidemiological patterns assumes that the trends of mortality correspond to certain changes in the incidence of diseases. presenting a pattern of mixed morbidity and mortality ${ }^{\prime}$.

This phenomenon emphasizes that, first, the group of infectious diseases is in decline but has not disappeared and has also given rise to other illnesses. such as AIDS; secondly. chronic-degenerative illnesses and accidents have increased; thirdly, permanent conditions include congenital malformations and perinatal problems ${ }^{\text {tit }}$.

In this sense, chronic diseases and accidents have progressed to occupy an important role among the causes of morbidity/mortality; eventhough the importance of the infectious disease persists in the mixed pattern still present in the principal causes of morbidity/mortality.

In economic terms, the meaning of changes in the epidemiological patterns specific to developing countries means an increase in the demand of care for costly diseases (treatment of chronic degenerative diseases and accidents) that will compete with the budget allocated for the treatment of infectious-contagious diseases even if these are incurable $e^{7,16: 20}$.

Examples of budget competition are cited in the studies of Rice, Hodgsone, and Kopstein who analyzed the direct costs (derived from the provision of services) in the United States for the treatment of heart disease which absorb $1.25 \%$ of the GDP and the indirect costs (productivity losses due to morbidity and premature death) account for $2 \%$ of the GDP: Based on the previous percentage and taking into consideration the increase of cardiovascular disease in Latin America, one can say that these diseases per se would be demanded in the future. Given the actual conditions of health expenditure, more than one third of the necessary expenses are required to be budgeted to treat them.

The growing demand for care is resulting in a process of economic crises and of low participation of health expenditure within the gross domestic product. In other words, the growing demand for care faces an economic barrier that will limit its resolution ${ }^{11.26}$. Nevertheless, one must consider that an increase in health expenditure means that it is necessary to revise the levels of efficiency in order to optimize the use of scarce resources?.

For the case of various Latin American countries, the health sector is not actually included among the priorities for public expenditure. In this regard. health expenditures for these countries have presented a serious deterioration in recent years accentuated by the commencement of the crises that began in the 1980 's, sinc which time the allocated resources have not followed the trends of total real government expenditure ${ }^{14}$.

This study aimed fundamentally to develop and implement a system for the monitoring of costs that would identify the cost of case management for each specific disease, and which could be used to validate and develop a methodologic budget in order to obtain the cost for specific disease in developing countries, taking for analysis two chronic-degenerative diseases and two infectiouscontagious diseases.

\section{Material and Methods}

This transversal study was conducted in a nationally-recognized general hospital. located in S. Paulo, Brazil, and adapted the criteria of Kessner for the determination of tracers ${ }^{1+1}$. After reviewing several studies on the cost of health services $^{i, 5.2 .2}$, a system of monitoring was applied to four selected diseases: breast cancer, enteritis, cardiac valve disease and bronchopneumonia.

The retrospective analysis was conducted through the selection of 120 hospital records. In accordance with the natural history of the diseases under study, seven previously designed instruments of data collection were applied to each of the records for the purpose of determining the standard procedures for the average case management. In addition, a multidisciplinary team (physicians, an economist. administrators, a nurse, and an epidemiologist) utilized the Delphi technique to arrive at a consensus regarding the identification of the procedures, functions of production and kinds of input that are involved in the process of case management. Further, this interdisciplinary team discussed the seven instruments and corrected those aspects neccesary to take into account the kinds of input. functions of productions and products, as well as all the activities before and after each function of production. During this stage, the physicians played the fundamental role 
in determining the different types of health interventions and the quality of the same.

These seven instruments include categories such as: infrastructure. human resources, laboratory and diagnostic studies, average length of stay in hospital, special therapy, disposable material, curing material, drugs, general and support services.

The forward analysis consisted of a shadow study of ten cases to validate the information provided by the multidisciplinary team with regard to the functions of production and the inputs required to satisfy the demand for each intervention.

Once the instruments were validated, the information necessary for the determination of the unitary cost and the average cost per case management was collected.

Finally, the cost matrixes by disease were designed in a computer package, the same one that integrated the health information system of the hospital.

\section{Results}

As the primary result of this study, a validated methodological approach was obtained for the determination of the cost of case management (Table) and the calculation of the costs of the func-

Table - Cost and definition for the case management of each disease included.

\begin{tabular}{lc}
\hline Disease & Cost (US dlls) \\
& \\
Brest Cancer & $\$ 1,646.00$ \\
Cardiac valve Disease & $\$ 3,456.00$ \\
Bronchopneumonia & $\$ 1,056.00$ \\
Diarriea & $\$ 2,220.00$ \\
\hline
\end{tabular}

- Case management of breast cancer: the average case management included a first time medical visit and 10 follow-up visits. Surgical intervention (mastectomy). Four day of hospitalization. Laboratory and diagnostic studies, 12 sessions of special therapy and chemoterapy.

- Case management of cardiovalve disease: the average case management included a first time medical visit and 6 follow-up visits. Surgical intervention for valve prosthesis. Eight days of hospitalization and one day of intensive therapy, Laboratory and diag. nostic studies and chemotherapy

- Case management of bronchopneumonia: the average case management by episode included a first time medical visit and follow-up visits. Five days of hospitalization. Laboratory and diagnostic studies and chemotherapy.

- Case management of diarrhea: the average case management by episode of chronic enteritis included a first time medical visit and seven follow-up visits three days of hospitalization. Laboratory nd diagnostic studies and chemotherapy.

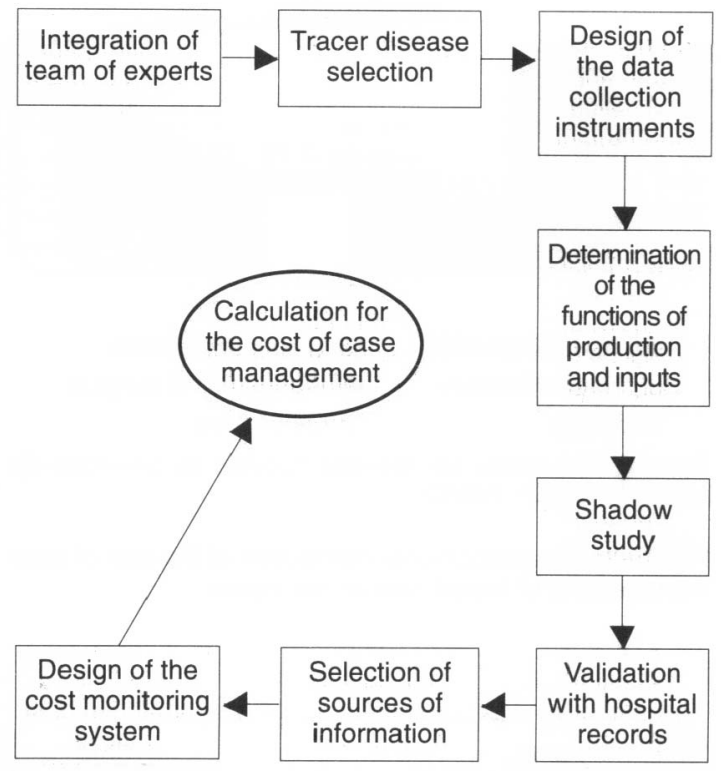

Figure 1 - Methodological steps for the determination of the cost per case management of four tracer diseases.

tions of production of health services in developing countries (Fig. 1).

The average cost information was obtained from the monitoring system. In the case of patients with cardiac valve disease (Fig. 2), the total cost of US $\$ 3,456,00$ was determined for case management. These costs were distributed in the following manner: human resources $(14.41 \%)$, laboratory and diagnostic tests $(3.88 \%)$, drugs and solutions $(1.52 \%)$, waste material and surgical $(71.51 \%)$, other costs $(8.68 \%)$. For patients with breast cancer (Fig. 3), a cost of $\mathrm{LS} \$ 1,646.00$ was determined for case management. These costs were distributed in the following manner: human resources $(29.85 \%)$, laboratory and diagnostic studies $(7.84 \%)$, drugs and solutions $(16.69 \%)$, special therapy $(12.76 \%)$,

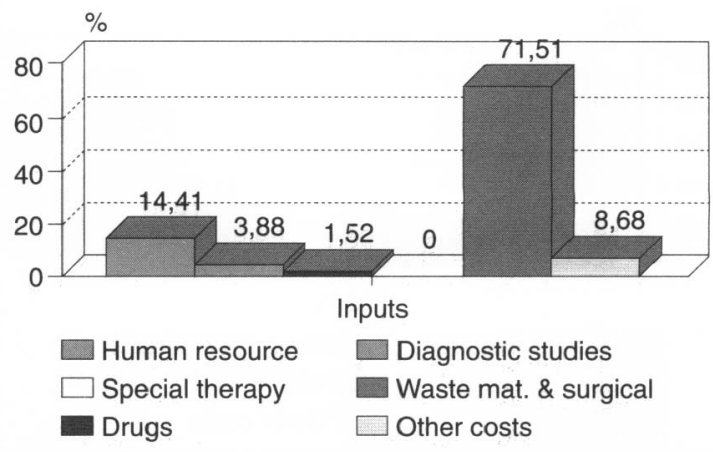

Source: cost matrix per disease "Costos de Servicios de salud en Brasil". PAHO ${ }^{21}$.

Flgure 2 - The proportional distribution of the cost of case management of cardlac-valve disease per inputs. 


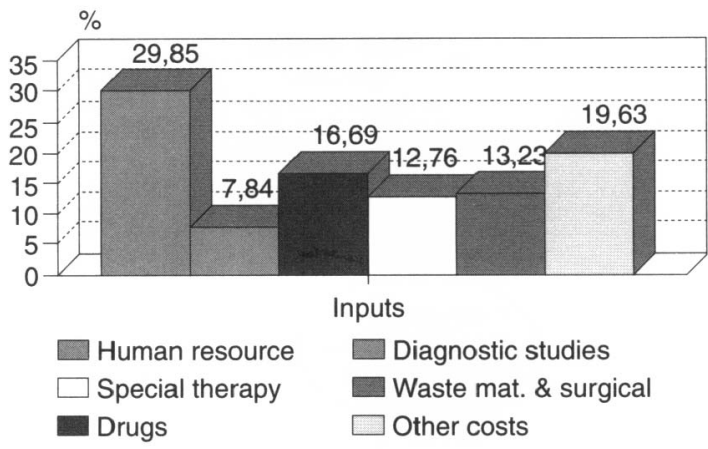

Source: cost matrix per disease "Costos de Servicios de salud en Brasil". PAHO ${ }^{21}$

Figure 3 - The proportional distribution of the cost of case management of breast cancer per inputs.

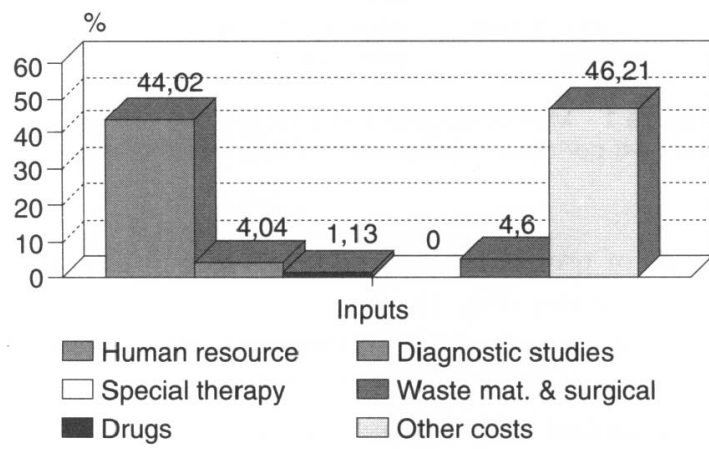

Source: cost matrix per disease "Costos de Servicios de salud en Brasil". PAHO ${ }^{21}$

Figure 4 - The proportional distribution of the cost of case management of bronchopneumonia per inputs.

waste material and surgical $(13.23 \%)$, other costs $(19.63 \%)$. For patients with bronchopneumonia (Fig. 4), a total cost of US $\$ 1,056.00$ was determined for case management. These costs were distributed in the following manner: human resources $(44.02 \%)$, laboratory and diagnostic studies

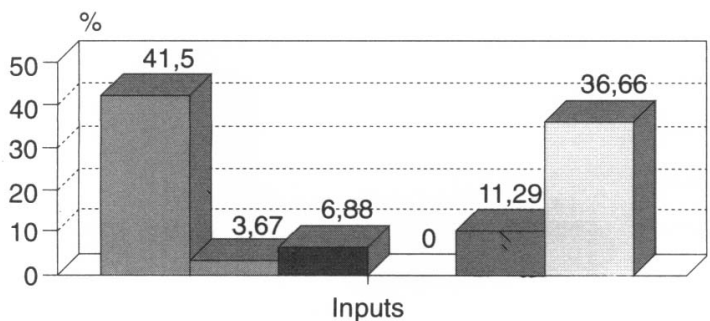

$\begin{array}{ll}\square \text { Human resource } & \square \text { Diagnostic studies } \\ \square \text { Special therapy } & \square \text { Waste mat. \& surgical } \\ \text { Drugs } & \square \text { Other costs }\end{array}$

Source: cost matrix per disease "Costos de Servicios de salud en Brasil". PAHO ${ }^{21}$

Flgure 5 - The proportional distributlon of the cost of case management of chronic enteritis per inputs.
$(4.04 \%)$, drugs and solutions $(1.13 \%)$, waste material and surgical $(4.6 \%)$, other costs $(46.21 \%)$. For patients with chronic enteritis (Fig. 5), a total cost of US $\$ 2,220.00$ was deternined for case management. These costs were distributed in the following manner: human resources ( $41.50 \%)$, laboratory and diagnostic studies $(3.67 \%)$, drugs and solutions $(6.88 \%)$, waste material and surgical $(11.29 \%)$, other costs $(36.66 \%)$.

\section{Discussion and Conclusions}

We must consider overall that this was a case study and that absolute data cannot be generalized in this type of study where the cost of the inputs will vary considerably even within the same institution. Nevertheless, the relative frequencies will be able to be replicated to any hospital or geographical location. The methodology of analysis is based fundamentally on the determination of disease specific costs apart from the natural history of the disease and is supported not only by groups of experts, but is also based on hospital records and the universal bibliography for each disease.

It may be concluded that there were three cost elements of greater relative weight in relation to the total cost for case management: human resources, waste material and surgical, as well as the cost of the bed per day.

Those findings could, in some sense, were expected if we consider, overall, that the human resources per hour is one of the critical inputs of medical care. The same occured in the case of waste material and surgical, as well as the cost of daily maintenance hospital. One must also take into account that the costs calculated were referred strictly to the direct cost of the hospital care. According to other authors, this triad represents the most important cost factor in the evaluation of hospital costs.

The findings that were not expected and that called our attention were relating to cardiac valve disease. The relatively most costly elements were waste material and surgical. The explanation of this is due to the high cost of medical prosthesis and waste material utilized in the intervention.

In relation to the total cost of standard case management, it is interesting to observe that the major cost corresponded to cardiac valve disease second only to enteritis. The previous called the attention to the fact that it was expected that the two chronic degenerative diseases were the most costly, however, breast cancer resulted in lower 
costs than enteritis. On the other hand. in comparing the total cost of the two chronic and the two infectious diseases, if is possible to observe that the cost of the former is practically double that of the latter.

The results of the study support the conclusion that in the short, medium and long term internal competition will be generated between chronic and infectious diseases in the use of the resources allocated to the health sector. Overall, if we take into account the assigned health care budget, the changes in the epidemiological profile are characteristic of any developing country. On the other hand. this methodological development and the implementation of systems to monitor costs allow the understanding of the different factors in cost. They generate information of high quality in the determination of charges for differential quotas, in the increase of productivity. in the search for new alternatives of financing and above, in the making of rational decisions by health care planners.

Finally, a very important result in this type of study is the need for the training of medical personnel in health economics and the study of this problem from an interdiscliplinary approach. Together an interdisciplinary team contributes a great deal to the needed and urgent incorporation of health economics in the analysis and solution of health care problems in developing countries. In this sense. the results of this study can lead to the creation of systems of monitoring costs that support decision making process. The cost centers integrated into the hospital information systems. a posteriori. will be the fundamental basis for the analysis of cost-effectiveness, cost-efficiency, and cost-benefit of the distinct aiternatives of intervention for the diseases under study.

In speaking of the financing perspectives for the production of health services, the challenges that health policies generate must be emphasised: including the process of integration of health services and the process of the public-private mix in the generation of services.

In order for the social investment in health to generate its maximum potential, and to combat the problems of equity, quality, accessibility, and efficiency, it is necessary to avoid the dispersal of investments. A paradoxical result demonstrates that this investment can have the "perverse effect" of reproducing the status quo rather than reducing social inequalities. That is exactly what occurs in a social system such as characterizes a country in which the fundamental concerns relate to the occupational and economic bases. In this sense, for national health systems. the search for viable formulas for integrating the providing of services constitutes a challenge and consequently, one of the most urgent tasks in the effective construction of a national health system which strives to attain its social objective.

\section{Acknowledgements}

This study was possible thanks to the Health Policy Program of the Panamerican Health Organization, Washington $D C$. We would also like to express our gratitude to the authorities of the health sector of S. Paulo, Brazil for the support that was given for the elaboration of this study.

\section{References}

1. ABL-ZFID, $H$. Health sertices utilizadion and cost in Ismalia. Egypt. Soc. Sci. Hed. 21: 451 61.1985 .

2. ARREDONDO. A. La incorporación de la perspectiva economica en el análisis del sector salud: antecedentes $y$ conceptos básicos. chad hed Soc Cbile. 34:115-22. 1992.

3. ATTANASIO, E. \& RLSCITTI, R. Contribution of accounting to the efficiency of health serrices: a study on the anatstic laboratorics of Roman Hospital. Epidemiol. Pret.. 9: 28-34. 198-.

t. BOBADILLA. J: FRFAK. I.: FREIKA, 'T". LOZAYO. R. Fulure changes in demographic epidemiologic and social factors. In: The etpidemiological transition and bealth primities wealth sector prionties reviell. Washington. D.C. The World Eank. 1990.
5. BRASSELR. I. An analysis of utilization. costs. funding and preadnission requirements of small college health senices. $f .4 \mathrm{~m}$. Coll. Health. 35: 101-t. 1986.

6. CRLZ. C. The impact of economic crisis and adjustment on bealth care in lifewico. Florence, International Child Development Centre LXICEF. 1991. (Occasional PapersTechnical keport $n^{2} 13$ ).

-. DLXLOP, D. W. Theoretical and empirical issues in bencefit. identification, measurement and raluation related to parasitic disease control in poor councries Soc. Sci. Hed.. 19:1031- - 1987.

8. FERREIRA. J. R. El liderazgo en salud pública en América. Educ. Héd. I' Salud. 23: 53+-9. 1989.

9. FETTER. R. Case mix definition by (DRGs) diagnosis related groups. .hed. Care Rev. 18:+153. 1980 
10. FREEMAN, J. Refined DRGs: trials in Europe. In: Workshop on DRS data production: Issues and Action for International Comparability. Proceeding, Dublin. The Economic and Social Research Institute. 1990. v. 1, p. $27-30$.

11. FRENK, J. Health transition in middle-income countries: new challenges for health care. Health Policy Plan., 4:29-39, 1989.

12. FRENK, J, Elements for a theory of the bealth transition, ponencia presentada en: bealth prionties review. Puebla, Banco Muncial, 1990.

13. JAMISON, D. \& MOSLEY, H. Disease control priorities in developing countries: health policy responses to epidemiological change. $\mathrm{Am} . \mathrm{J}$. Public Health, 81:15-22, 1991.

14. KELSEY, J. Methods of tracing of study subject in methods. In: Observational epidemiology. New York, Oxford Univ, Press, 1986 p. 101137.

15. KESSNER, D. Assessing health: the case for tracers. $N$. Engl.J. Med., 288: 189-94, 1973

16. LEE, K. \& MILLS, A. The economics of bealth in developing countries. New York, Oxford University Press, 1983.

17. MÁRQUEZ, P. Control de costos en salud: experiencias en países de las Américas. Bol Oficina Sanit. Panam., 109: 111-27, 1990.

18. MCPAKE, B. The health sector in the 19805 and 1990s. In: Reestructuring the bealth sector in developing countries: occasional paper sbort course. London, School of Hygiene and Tropical Medicine, 1991, p 5-29.
19. MUSGROVE, P. Crisis económica y salud: la experiencia de cinco paises Latinoamericanos en los años ochenta. Washington D.C., PAHO, 1989.

20. MUSKIN, S. Health as an investment. $J$. Polit. Econ., 5:129-57, 1962.

21. PAN AMERICAN HEALTH ORGANIZATION Condiciones de Salud en las Américas 19851990. Washington, D.C. 1990. v. 1 (OPASPubl. Cient., 524).

22. POMMER, E, \& WIEBRENS, C. Cost and financing of health services for aged in the 80s. Gerontol. Geriatr. Rev., 15: 203-9, 1984.

23. RICE, D.; HODGSON, P.; KOPSTEIN, N. A. The economic cost of illness: a replication and update. Health Care Finan. Rev, 7:61-80, 1985.

24. ROBERTSON, R, Review of literature on costs of bealth services in developing countries. Washington, D.C., Population, Health and Nutrition Department/World Bank, 1985.

25. ROBERTSON, R. Primary health services in Ecuador: comparative costs, quality, and equity of care in Ministry of Health and rural social segurity facilities. Soc. Sci. Med., 32: 1327-36, 1991.

26. STASTXA, M. Problems in expressing performance in relation to costs in the health services. Cesk-Zdrav, Rev, 38; 155-61, 1990.

27. WORLD HEALTH ORGANIZATION. Economic research into bealth service growth; report on a WHO Worksbop. Copenhaguen, Oficina Regional de la OMS para Europa, 1981 p. 3946. (ELRO Reports and Studies 52).

\begin{abstract}
Resumo
São estudados os resultados de parte da necessidade de se desenvolver mátodos para a análise de custos em paises am desenvolvimento, principalmente na regiăo da América Latina. Pretendeu-se gerar conhecimento a partir de uma avaliação económica, para apolar a tomada de decisరés na organização de sistemas de saúde, particularmente no uso eficiente dos recursos destinados aos serviços médicos. Foram seleccionadas duas doenças crónicas (câncer de mama e valvulopatia) e duas infecciosas (enterite e broncopneumonia), para serem estudadas. Os resultados permitiram recomendar o uso da metodologia valldada para a análise económica de custos de qualquer outra doença que se necessite estudar, bem como o uso da informação para tomar decisōes.
\end{abstract}

Custos de cuidados de saúde. Controle de custos. 